\title{
Aborto, direitos reprodutivos e feminismo na França de Nicolas Sarkozy
}

No início de 2009, o presidente Nicolas Sarkozy anunciou em seu projeto anual de lei de finanças uma redução de $42 \%$ no efetivo destinado às ações do Conselho Conjugal e Familiar francês, que passaria de 2,5 milhões de euro a 1,5 milhões. Imediatamente, associações ligadas ao planejamento familiar se mobilizaram para protestar contra a medida, que poderia levar ao fechamento de 70\% de centros dedicados à informação sobre a concepção na França. É neste contexto que surge a associação Osez le Féminisme (Ouse o feminismo), um grupo de jovens que decide se organizar para reivindicar no espaço público a manutenção dos direitos sexuais e reprodutivos que parecem ameaçados pela política sarkozista de reequilíbrio orçamentário.

No presente artigo, pretendo refletir sobre a recente história da associação e sobre como ela ilustra a maneira como o tema do aborto é pensado hoje pelas jovens feministas francesas - muitas nascidas depois da promulgação da lei que o tornou legal na França. Tenho a intenção de indicar que tal problemática se constrói numa negociação constante entre o reconhecimento dos combates feministas considerados clássicos e a adequação à situação política atual. Dito de outra forma, desejo tomar Osez le Féminisme (a partir de agora referido como OLF) como tela de fundo servindo à projeção da apresentação da discussão sobre o aborto na França de Nicolas Sarkozy. Entre a certeza da legitimidade do direito das mulheres ao aborto e as dificuldades em garantir este direito encontradas pelos serviços hospitalares, podemos localizar uma lacuna que a ação militante feminista da associação tem a intenção de tornar visível. 


\section{A Lei Veil e o aborto na França}

Desde a promulgação da Lei Veil, em janeiro de 1975, o aborto é descriminalizado na França. Simone Veil, então ministra da Saúde, pronunciou um discurso histórico em 26 de novembro de 1974 defendendo o novo projeto de lei. $\mathrm{O}$ argumento central por ela apresentado era o de que médicos, servidores sociais e cidadãos já se viam compelidos a participar de "ações ilegais" para ajudar as mulheres que decidiam interromper sua gravidez :

Eles sabem que, ao recusar conselho e apoio, estão abandonando [a mulher] na solidão e na angustia de um ato perpetuado nas piores condições e que periga deixá-la mutilada para sempre. Sabem que essa mesma mulher, se ela tem dinheiro, se ela sabe se informar, irá a um país vizinho, ou mesmo a certas clínicas na França, e poderá, sem correr risco nem ser penalizada, interromper sua gravide ${ }^{1}$.

No ano de 1974, o número de mulheres que realizavam aborto por ano da França era 300.000 (hoje este número está em torno de 220.000, de acordo com estatísticas do Ministério da Saúde, como indicarei em seguida). Essas mulheres, afirmava Veil, "não são necessariamente as mais imorais ou as mais inconscientes", mas pessoas que frequentamos e das quais ignoramos o sofrimento. Parecia fundamental naquele momento legalizar e assim tornar menos opaca, além de menos injusta, uma situação que já era a realidade de muitas mulheres.

A Lei Veil estipula a suspensão de penalizações legais quando a interrupção voluntária de gravidez é praticada antes da décima semana, por um médico, num estabelecimento público ou privado que satisfaça condições preconizadas pelo código de saúde pública. Ela estabelece que a mulher pode pedir a seu médico uma interrupção e que este deve encaminhá-la a um "estabelecimento de informação" que lhe atribuirá um atestado de consulta. Essa consulta visa oferecer assistência e conselho à mulher, além de indicar-lhe meios para resolver eventuais "problemas sociais" decorrentes da gravidez. Entre a comunicação ao médico da intenção de abortar e o procedimento, um prazo de pelo menos uma semana deve ser respeitado. No caso de a mulher ser menor de idade e solteira, uma autorização de um dos pais ou de um representante legal é exigida.

Disponível em: http://www.assemblee-nationale.fr/histoire/interruption/simone_veil_tribune-1.asp, acessado em junho/2011. 
Desde a sua adoção, a lei sofreu melhorias significativas. A partir de 1982, houve uma modificação que garantiu que o procedimento de interrupção voluntária de gravidez também fosse reembolsado pelo sistema público de saúde - o que antes era o caso apenas para as interrupções médicas, ou seja, quando há risco de saúde para mãe e/ou quando o feto sofre de doença grave e incurável. E desde julho de 2001, a lei no 2001-588 aumentou o prazo legal de 10 para 12 semanas e deixou de exigir a autorização dos pais para mulheres menores de idade.

\section{“Ouse o feminismo"}

Trinta e quatro anos depois da promulgação da Lei Veil relativa à interrupção voluntária da gravidez, em junho de 2009, certas diretrizes propostas pelo governo no projeto anual de lei de finanças tornariam inviável a manutenção de todos os centros que garantem o acesso ao aborto nos hospitais franceses. Diante da possibilidade de fechamento de um terço dos centros de planejamento familiar por toda a França, um grupo de jovens (mulheres e homens) que se definem como feministas não-revanchistas se forma para participar de atos de apoio ao Planning Familial². É o início de Osez le Féminisme. Como afirma seu texto de apresentação, a associação é criada a partir da constatação de que direitos há muito adquiridos não permanecem garantidos para sempre:

As mobilizações do movimento feminista ao longo do século XX não apenas nos permitiram ganhar direitos para as mulheres, mas também fazer evoluir as mentalidades. Sabemos que a melhoria de condições de vida e de trabalho das mulheres não é automática e que a marcha em direção à igualdade é uma batalha a ser travada permanentemente. Também sabemos que os avanços obtidos (direito à educação, direito à disposição de seu corpo, etc...) o foram graças à relação de força construída pelo movimento social, o movimento feminista e as lutas políticas ${ }^{3}$.

A associação se apresenta como um coletivo promotor de ações públicas que visam sensibilizar a sociedade civil quanto à importância atual da luta feminista. Nesse sentido, a articulação entre a herança das aquisições

\footnotetext{
Fundada nos anos 1950 para defender o acesso à contracepção e ao aborto, então proibidos por lei, Le Planning Familial é uma organização não-governamental francesa ligada aos direitos reprodutivos e à sexualidade (NE).

Apresentação da associação no site osezlefeminisme.fr.
} 
de combates feministas precedentes e as temáticas próprias à França desta década funciona como a espinha central da atuação da OLF. Uma de suas fundadoras, Caroline de Haas, explica que

ainda que as prioridades [do combate feminista de hoje] não sejam as mesmas que há 150 anos - é claro que não vamos lutar por uma lei pelo aborto ou pelo direito ao voto - o cerne da questão segue o mesmo: na nossa sociedade persistem os estereótipos (...) sobre as mulheres e os homens (...). Pensamos que as mulheres e os homens têm papéis diferentes na sociedade e então não nos chocamos com a inegalidade salarial, com os 75.000 estupros por ano (na França), que existam apenas 20\% de mulheres na Assembleia Nacional (De Haas, 2011).

As ações de OLF se situam assim entre as prioridades consideradas como clássicas no meio do ativismo feminista, e a tentativa (ainda tímida, segundo seus críticos - ver seção “Feminismo jovem/feminismo novo?”) de expandir o campo dos sujeitos que se sentem contemplados pela denominação e pelo combate feminista. Isso significa se fazer visível em debates tão variados quanto a lei da paridade entre mulheres e homens no Senado e a luta contra a lesbofobia no trabalho. Essa multiplicidade de temáticas fica evidente quando se observa a lista de temas tratados pela publicação da associação, um jornal enviado pelo correio para os aderentes e disponibilizado no site osezlefeminisme.fr. Até hoje, foram feitos números consagrados aos seguintes assuntos: violência contra as mulheres, religião e direitos das mulheres, igualdade profissional, a imagem das mulheres na publicidade, a igualdade mulher-homem na política, o prazer feminino, maternidade, educação, mulheres no mundo das artes, aborto, estupro, mulheres e esporte, prostituição e heteronormatividade.

Além do jornal, publicado seis vezes por ano, a associação organiza uma reunião pública por mês. Peça central do funcionamento da associação, é nela que são debatidos os temas da próxima publicação e que são agendadas as intervenções do grupo: atos públicos, participação na mídia, criação de campanhas, organização de formações. A esta grande reunião mensal, que chega a reunir 100 pessoas em uma sala disponibilizada por uma filial do Planning Familial de Paris, somam-se nove outras menores, organizadas em torno de temas específicos, tais como a laicidade e a solidariedade internacional, a mercantilização do corpo, a luta contra as violências e o estupro ou o feminismo LGBTT. 
A associação se mantém graças às doações e à assinatura do jornal, que dá às assinantes o título de associada e o direito de votar nas Assembleias Gerais do grupo. O número de associadas se aproximava de mil em julho de 2011, muitas delas recém-associadas como reação ao tratamento dado pela mídia francesa às acusações de estupro contra Dominique Strauss-Khan, ex-diretor do Fundo Monetário Internacional e personalidade importante do Partido Socialista francês. No domingo seguinte à prisão preventiva de Strauss-Khan, e em repúdio às inúmeras declarações de apoio que ele recebeu (muitas de caráter explicitamente sexista), OLF, junto com outras associações feministas como La Barbe e Paroles de Femmes, organizou uma manifestação em Paris. A presença de 3.000 pessoas e a cobertura pela mídia nacional e internacional deu grande visibilidade ao grupo e atraiu novas aderentes.

\section{O aborto na França hoje: uma situação paradoxal}

Como indicado, a primeira ação de OLF foi a mobilização contra os cortes nas subvenções atribuídas aos centros de planejamento familiar. O resultado dessa ação, que incluiu passeatas por toda a França em janeiro de 2009, foi uma redução de créditos menor do que a prevista inicialmente (uma passagem de 2,5 milhões de euro a 2,2 milhões) na Lei de Finanças de 2009, além de uma promessa do ministro do Trabalho e da Família, Brice Hortefeux, de não fechar nem abandonar nenhum centro de planejamento familiar.

$\mathrm{Na}$ França, segundo relatório da Inspection Générale des Affaires Sociales (Inspeção Geral para Assuntos Sociais, IGAS), são realizados cerca de 220.000 abortos $/ \mathrm{ano}^{4}$. Esse número não parece variar muito apesar de melhorias significativas na distribuição de métodos contraceptivos, o que leva os autores do relatório a descrever o contexto francês como paradoxal. $\mathrm{Na}$ verdade, coexistem na França três fenômenos que pareceriam incompatíveis, a saber: a taxa de natalidade mais alta da Comunidade Europeia (em torno de 12 nascimentos/1000 pessoas), uma das mais altas taxas de difusão de contraceptivos no mundo e uma taxa de aborto que não diminui e permanece a um nível relativamente elevado.

Segundo o mesmo relatório da IGAS, um quarto dos procedimentos de interrupção de gravidez acontece em apenas quarenta e três estabelecimentos,

Disponível no site do Ministério da Saúde: http://www.sante.gouv.fr/IMG/pdf/Rapport_sur_les_politiques_de_prevention_des_grossesses_non_desirees_et_de_prise_en_charge_des_IVG.pdf, acessado em junho/2011. 
responsáveis então por mais de 1.000 abortos por ano. Diversos hospitais decretam não poder praticá-los (especialmente no caso de interrupções consideradas tardias, próximas da $14^{\mathrm{a}}$ semana de amenorréia, ou seja, da $12^{\text {a }}$ semana de gravidez) e encaminham as mulheres a outros centros. $\mathrm{Na}$ região parisiense, o tempo médio de espera para se conseguir uma consulta nos hospitais públicos é de três semanas.

A manutenção dos centros de planejamento familiar e do acesso indiscriminado aos centros de aborto nos hospitais representa uma faceta interessante do debate sobre a saúde reprodutiva na França nos anos 2010, construída no entrelaçamento das reivindicações clássicas do feminismo com um certo sentimento de surpresa face à persistência das mesmas problemáticas. Dito de outra forma, o engajamento político que une as militantes de OLF se situa entre a consciência da importância do direito ao aborto e a percepção que, mesmo na França laica e republicana na qual cresceram, um tal direito fundamental pode ser ameaçado.

É interessante notar que o direito ao aborto não é em nenhum momento questionado nem por membros do governo nem pela sociedade civil. Mesmo Marine Le Pen, futura candidata à presidência nas eleições de 2012 pelo Front National (partido de extrema direita), se distanciou da posição historicamente defendida por seu partido contra o aborto e afirmou que, apesar de não poder se sentir feliz com o número de abortos realizados anualmente na França, não tem a proibição como projeto e diz desejar que as mulheres decidam (ainda que isso queira dizer, para ela, propor-lhes uma renda caso decidam não abortar $)^{5}$.

No entanto, o fato de o aborto ser percebido como um direito fundamental pela maior parte da população não significa que, na prática, ele esteja garantido sem entraves para todas as mulheres. E foi essa constatação que serviu como motivação para a criação da OLF, ou seja, a luta para evitar que os direitos das mulheres (muitas vezes já declarados por leis) deixem de ser assegurados por articulações políticas que acabam tornando o acesso a tais direitos inviável. No caso específico do direito ao aborto, trata-se de militar não por uma lei que o garanta (visto que esta já existe), mas contra a diminuição do número de funcionários nos blocos de operação, por exemplo.

Ver, por exemplo, sua participação no programa A vous de juger, 03/03/2011, disponível em http:// www.frontnational.com/?cat=53_ (acesso em junho/2011). 


\section{Direito à contracepção, direito ao aborto}

O ponto central defendido por OLF e pelo Planning Familial em relação ao aborto é o de que o direito à contracepção e o direito ao aborto não são opostos, mas sim complementares quando se trata da autonomia reprodutiva da mulher. Essa afirmação vem da constatação de que não existe o que o relatório do IGAS chama de "risco concepcional zero", ou seja, toda mulher heterossexual sexualmente ativa pode um dia se confrontar com uma gravidez indesejada. A expectativa de um controle total da fecundidade não é realista e isso independe das estratégias de prevenção. Segundo trabalhos como o de C. F. Westhoff (1988) citado pelo IGAS, o aumento em 50\% da prevalência da prevenção diminui em apenas $32 \%$ o número de abortos

Como explicita o relatório da IGAS, os fatores que levam a uma gravidez indesejada e a decisão de interrompê-la são "múltiplos, complexos e escapam em grande parte à intervenção pública”. Por isso a sugestão de que o aborto não seja considerado como um evento excepcional, mas sim como um componente estrutural da vida sexual e reprodutiva. Já que é provável que cerca de $40 \%$ das mulheres na França se veja um dia confrontada a uma gravidez indesejada - "a aderência [a um tratamento] não é jamais total, nem em caso de doenças graves; em relação à pílula, um esquecimento um dia é igual a uma gravidez", explica a presidenta do Planning Familial, Carine Favier (Le Monde, 22/4/2011) -, é preciso que o Estado se posicione face a esta realidade.

É interessante retomar a afirmação do relatório da impossibilidade das políticas públicas de controlar totalmente o número de gestações não desejadas. Ela funciona como um dos pontos centrais que permite às feministas de OLF mobilizar a sociedade civil pela manutenção dos centros de planejamento familiar. Trata-se de tornar pública a mensagem de que o aborto não deve ser tratado como um "fenômeno residual", cuja [extinção] depende da aplicação de medidas adequadas. As diversas ações do grupo - descritas abaixo - visam associar constantemente as discussões sobre o aborto com as discussões sobre o chamado "fracasso contraceptivo", ou seja, a possibilidade de que qualquer método falhe. O objetivo é tentar separar a representação [social] do aborto como estando ligado a um grupo etário ou socioeconômico específicos (mulheres mais jovens e população dita "de risco", por sua maior vulnerabilidade socioeconômica), tratando-o a cada vez como uma questão que diz respeito a todas as mulheres. E, como consequência, 
exigir do sistema público de saúde uma solução segura para a interrupção da gravidez não planejada. No momento das passeatas de protesto contra as medidas de redução das subvenções atribuídas ao planejamento familiar, faixas dizendo "Esqueci de tomar a pílula, o que faço? A República Francesa diz: se vira" eram comuns.

\section{Feminismo jovem, feminismo novo?}

Numa entrevista à televisão reproduzida por Xavier Gauthier, Simone Veil afirma, sobre a aprovação da lei Veil em 1974:

Eu não queria que o debate desviasse para o terreno da liberdade do corpo. Era preciso insistir na proteção indispensável da mulher que sofre. Era preciso evidenciar o tema da dignidade. As francesas, favoráveis em sua imensa maioria à liberdade de abortar, não queriam dizer à sociedade: "faço o que quero do meu corpo"; elas reclamavam o direito de tornar audível o grito "Não quero ter um filho dessa vez. Não tenho mais forças”. (Gauthier, 2002)

Ela diz na entrevista que, para ela, toda a mulher deve dispor de seu corpo como bem entende, mas, no momento dos debates sobre a lei, sua intenção era "ganhar", ou seja, aprová-la. Para isso, fez a escolha de apresentá-la como reparadora de uma situação injusta e traumatizante. Optou por não defender face à Assembleia um discurso condizente com o que os movimentos feministas da época já pregavam, a saber: o dos direitos da mulher a disporem de seu corpo (como o famoso slogan "um filho quando eu quiser, se eu quiser"). Com o forte argumento de que aumentaria as chances de aprovação da lei se se posicionasse de outra maneira, Veil apresentou-se como mulher falando em nome de mulheres vítimas da obrigação de cuidar de uma criança não planejada.

Esta articulação entre a necessidade de "ganhar" as batalhas e as concessões que se deve fazer para isso causou menos polêmica nos anos 70, momento de aquisição de um direito fundamental como o aborto, do que hoje, na França laica e republicana de OLF. O tema da proteção da mulher-vítima, utilizado por Veil como argumento em 1976, está no centro das críticas feitas à associação por organizações, tais como Act-Up (de luta contra a AIDS) ou STRASS (Sindicato d@s Trabalhador@s do Sexo). Esses grupos discordam das posições assumidas por OLF em relação principalmente à prostituição e a acusam de considerar as mulheres sempre como vítimas. 
São grupos que defendem a legalização da prostituição e que argumentam que a posição abolicionista não é o que melhor convém as trabalhadoras e trabalhadores do sexo.

Além da questão da prostituição, OLF também é criticada por não apoiar a gestação substituta e por sua desaprovação da indústria pornográfica. De modo geral, um olhar crítico sobre a associação permite questionar o espaço que há na atuação militante de suas associadas para a formulação de "novas questões feministas", aqui entendidas como mais distanciadas de temas classicamente presentes na história do feminismo francês (como é o caso da representação das mulheres na política, dos dispositivos que permitem às mães retornarem ao trabalho, da prostituição). Dito de outra forma, o trabalho político de OLF se apoia mais nas temáticas da chamada segunda onda feminista do que nas problemáticas trazidas pelos estudos de gênero e estudos culturais, a partir dos anos 90 .

É dessa forma que o feminismo jovem de $\mathrm{OLF}^{6}$ participa do que a historiadora C. Taraud chama de "feminismo mosaico" francês, uma composição bastante heterogênea sob a qual se abrigam discursos muitas vezes contrastantes. Em seu livro de entrevistas Les féminismes en question (Feminismos em questão), publicado em 2005, ela descreve a "coabitação improvável” de campos que se constituem a partir de posições teóricas bem definidas, mas ainda assim móveis. Chama-lhe a atenção o aspecto aleatório das estratégias utilizadas por seus entrevistados, assim como o caráter conjuntural das alianças que formam (Taraud, 2005): como se as reflexões e ações nas quais se engajam carregassem sempre a marca do percurso individual de cada um dentro do que entende como feminismo.

\section{Conclusão: o que há de novo no direito ao aborto?}

Em novembro de 2009 a CADAC (Coordenação das Associações pelo Direito ao Aborto e à Contracepção) organizou uma passeata para defender o direito ao aborto. Ao receber o panfleto que convidava para a manifestação, uma das participantes da reunião de OLF que tratava do tema exclamou que nunca imaginou que ainda estaria participando desse tipo de passeata aos sessenta e cinco anos. Essa surpresa quanto à persistência de temáticas tradicionais nas atividades de associações feministas parece indicar um

Enunciado, por exemplo, numa reportagem do jornal Libération que tinha como título "Nem 30 anos e já feministas" (A peine 30 ans, déjà féministes. 16/10/2009). 
aspecto interessante da figura do mosaico proposta por C. Taraud. Trata-se da oscilação entre a crítica a um feminismo pouco "subversivo"7 e o reconhecimento da importância de discussões sobre temas tido como históricos, como o direito ao aborto.

Entre o "cansaço" de fazer sempre as mesmas campanhas - descrito de modo contundente num editorial de Nouvelles Questions Féministes já em $1992^{8}$ - e a percepção da relativa fragilidade dos direitos adquiridos nessas mesmas campanhas, as feministas da França de Nicolas Sarkozy ainda colocam o tema do aborto numa posição importante no espaço público. Independentemente da longevidade da lei e do apreço demonstrado pela população ao direito de abortar, persiste a certeza de que este é um direito vulnerabilizado por transformações no sistema de financiamento dos hospitais. Ele se sustenta assim num espaço contraditório de novidade tradicional, no qual um tema clássico sinaliza transformações recentes num cenário familiar. Dessa forma, se constitui como via importante para a reflexão não apenas sobre os direitos sexuais e reprodutivos, mas também sobre o Estado francês. A questão do aborto hoje, mais de trinta anos depois da legalização, se mantém relevante tanto para a militância política quanto para os estudos de sexualidade e gênero.

\section{Referências bibliográficas}

BUTLER, Judith. 1990. Trouble dans le genre. Pour un féminisme de la subversion. Paris: Découverte.

DE HAAS, Caroline. 2011. "Le jour où Sarkozy sera féministe, ça se saura". Charlie Hebdo Hors Série, abril-maio, n. 29, p. 14-16.

DELPHY, Christine. 1992. "Avertissement aux malfaisants". Nouvelles questions féministes, v. 13-14, p. 1-5.

GAUTHIER Xavier. 2002. Naissance d'une liberté. Paris: Robert Laffont.

TARAUD, Christelle. 2005. Les féminismes en questions: éléments pour une cartographie. Paris: Amsterdam.

O termo subversivo é utilizado em referência ao subtítulo do trabalho de Judith Butler, Problemas de gênero, considerado um marco nos estudos feministas não-baseados numa dita identidade feminina. Ver Butler (1990).

8 "Nós estamos cansadas de fazermos sempre as mesmas campanhas, de dizer por meses, anos, décadas, séculos, os mesmos argumentos" (Delphy, 1992). 
FAVIER, Carine. 2011. “Contraception et avortement: des droites irréfragables et complémentaires pour l'autonomie des femmes”. Le Monde, 12 de maio. WESTHOFF, Carolyn F. 1988. "Contraceptive paths towards the reduction of unintended pregnancy and abortion”. Family planning perspectives, v. 20, p. 4-13.

\section{Documentos eletrônicos}

Apresentação de Osez le Féminisme: osezleféminisme.fr

Participação de Marine Le Pen no programa A vous de juger:

http://www.frontnational.com/?cat=53_

Vídeo do discurso de Simone Veil na Assembleia Nacional:

http://www.assemblee-nationale.fr/histoire/interruption/simone_veil_ tribune-1.asp, acessado em junho/2011.

Reportagem do jornal Libération sobre o financiamento do Planning familial: http://www.liberation.fr/societe/0101316915-hortefeux-cede-sur-le-planning-familial, acessado em junho/2011.

Relatório do Ministério da Saúde sobre as políticas de prevenção de gravidez: http://www.sante.gouv.fr/IMG/pdf/Rapport_sur_les_politiques_de_prevention_des_grossesses_non_desirees_et_de_prise_en_charge_des_IVG. pdf, acessado em julho/2011.

\section{Resumo}

Neste texto, apresento uma análise das ações da associação feminista francesa Osez le Féminisme (Ouse o feminismo) em seu combate para garantir a manutenção dos centros médicos onde é praticado o aborto. A atuação do grupo serve como pano de fundo no presente trabalho para uma reflexão sobre a maneira como jovens feministas, nascidas após a promulgação da lei que tornou o aborto legal na França, pensam esse direito.

Palavras-chave: aborto; feminismo; França; saúde pública.

\section{Abstract}

This article presents an analysis of the actions of feminist association Osez le féminisme (Dare to be a feminist) and its struggle to maintain health centers where abortion services are provided in France. The association's actions serve as a background to illustrate the way young feminists born after abortion was made legal in France think about this question.

Key words: abortion; feminism; France; public health.

Recebido em julho de 2011.

Aprovado em setembro de 2011. 